DOI: 10.24867/MD.9.2017.2.61-64

Research paper

\title{
IMPROVEMENT OF TURBO-DIESEL IC ENGINE WITH ELECTRIC COMPRESSOR
}

\author{
Jovan DORIĆ1, * \\ 1 University of Novi sad, Faculty of Technical Sciences, Novi Sad, Serbia
}

\section{Received (10.04.2017); Revised (14.06.2017); Accepted (16.06.2017)}

\begin{abstract}
It is well known that modern trend of IC engine development going towards increasing of power and reduction of fuel consumption and engine pollution. Modern motor vehicle is usually powered with IC engine especially with turbocharged internal combustion engine. In this paper was shown one possible way for improvement of charged IC engine performance. Results shown that with electric compressor in the range of lower engine speed power and torque can be increased.
\end{abstract}

Key words: I.C. engine, wear, polar diagram

\section{INTRODUCTION}

Today's trends of IC engines development going towards reduction of engine size and displacement. It can be said that the main characteristics of today's engine is very small amount of work in relation to used fuel, in other words, today's engines have a very low coefficient of efficiency. Realistically speaking Otto engines today use about $25 \%$ of input energy, while diesel construction about $30 \%$ (in some cases can be expected a little more). Approximately $35 \%$ of the petrol engine and $30 \%$ of heat in the diesel engines goes through exhaust and around $33 \%$ goes for cooling the engine in both versions, other $7 \%$ is attributed to friction and radiation. The last couple years has seen a flurry of petrolpowered medium-sized vehicles downsizing from their usual six cylinders to just four. Downsizing is a simple concept, replace a larger engine with a smaller version, with a lower displacement. The downsized engines of tomorrow will have fewer, smaller cylinders, so the volume swept by pistons as they pump up and down inside is reduced. This will reduce friction, thermal losses and the mass moved, boosting fuel economy and cutting carbon dioxide emissions. The engine that powered first car built by carl Benz 140 years ago developed a power of $0,6 \mathrm{~kW}$ with displacement of about liter. Today's automotive engine have power density of more than $100 \mathrm{~kW}$ per liter. These achievements of larger engine power from the same or smaller engine displacement are possible due application of higher pressure in cylinder engine. Modern engines usually have one or more turbocharders. As it is known today, is a very popular to construct a turbocharged engine to reduce the weight, dimensions and consumption of the vehicles. The idea of increasing power with turbocharger is old as the principle of reciprocating internal combustion engine, the first patent related to supercharging combustion engines dating back to 1885 .
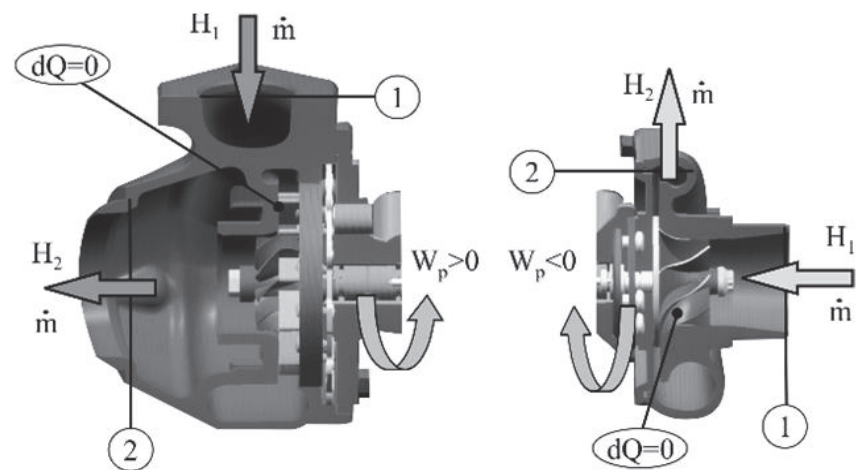

Fig. 1. Mass and energy flow: a) turbine and b) compressor

One of the reasons for using turbocharging in combustion engines is to achieve more complete expansion of the working body. For an extension of expansion requires a large volume of working space, which irreversibly increases power losses. The basic thermodynamic description of the image of a turbocharger can be seen in Fig. 1. In this work, the analysis will be made of the engine with a turbocharger with added an electrical compressor, which aims to improve the performance of the engine at low rpm.

\section{ELECTRIC COMPRESSOR}

Electric compressor is a special type of compressor which uses electric powered system to compress air and its delivery to the engine. It is designed with the aim to correct the performance of the engine in the rpm range where the current types of compressors have shown poor results. Improvement of torque in turbocharged engine with electric compressor can be seen in Figures 2 and 3 


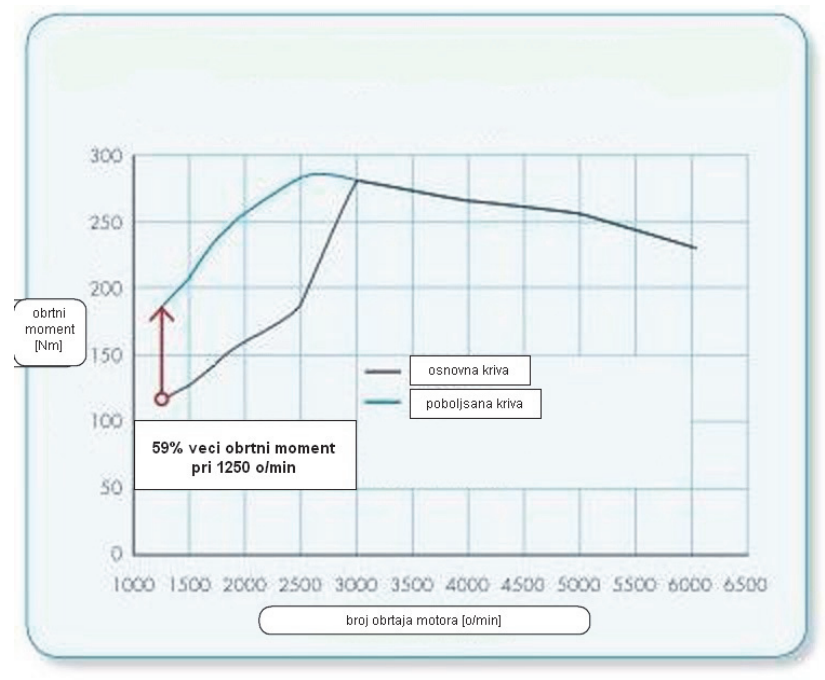

Fig.2. Torque improvement with electric compressor on turbocharged engine

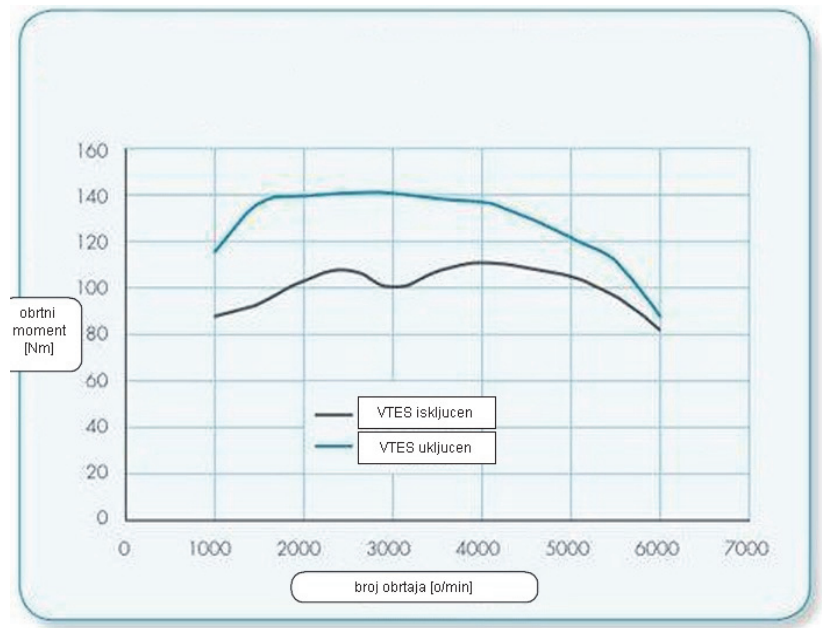

Fig.3. Torque improvement with electric compressor on natural aspirated engine

There is no special restrictions in its application on ordinary internal combustion engines. Today, there are different versions of electric compressor, one possible way is shown in Figure 4.

Electric compressor in most cases have direct connection to the battery of a motor vehicle, thereby achieving complete autonomy in the compressor. On the other hand, the total electricity consumed by the compressor is greater than the energy produced by a factory-built alternator and therefore resorted to placing major or alternator, which is a topic of recent discussions, the transition to 48 - volt electrical system of the vehicle. This would enable the use of smaller conductor cross-section for the power supply to the compressor and the use of electric compressors were profitable. Generally, losses of this solution compressors are greater than the losses when the compressor mechanically drives directly from the crankshaft. There is also possibility to use recovery of electricity produced by excess kinetic energy of gases, then thus can replace the energy consumption required for recharging the battery (which has been the guiding principle in the construction of a centrifugal compressor with additional electric actuator). In designing the compressor performance special attention should be paid to the fact that the electric motor works near the source of the enormous heat at speeds that reach up to $100000 \mathrm{o} / \mathrm{min}$.

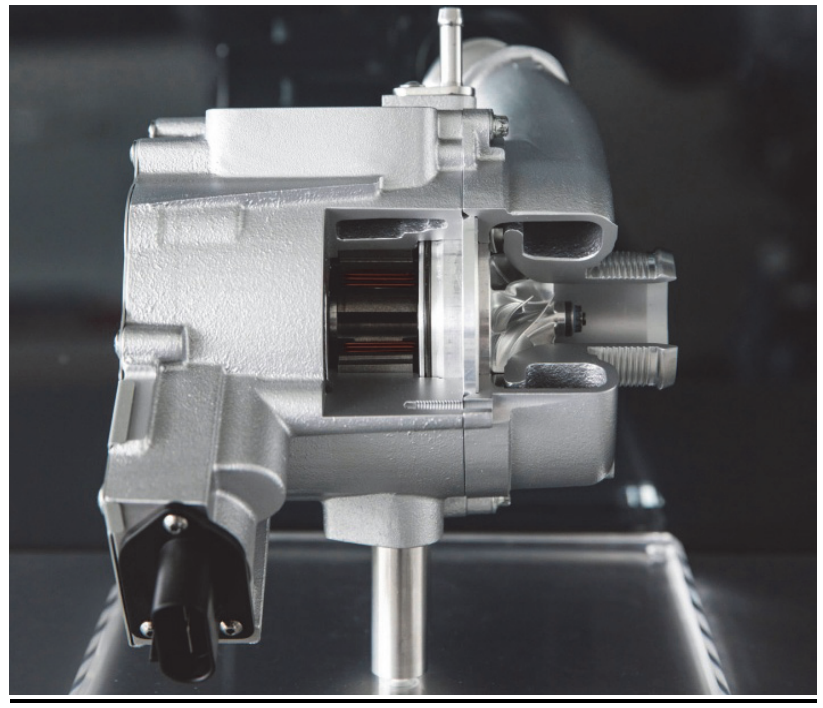

Fig.4. One possible way for electric compressor design

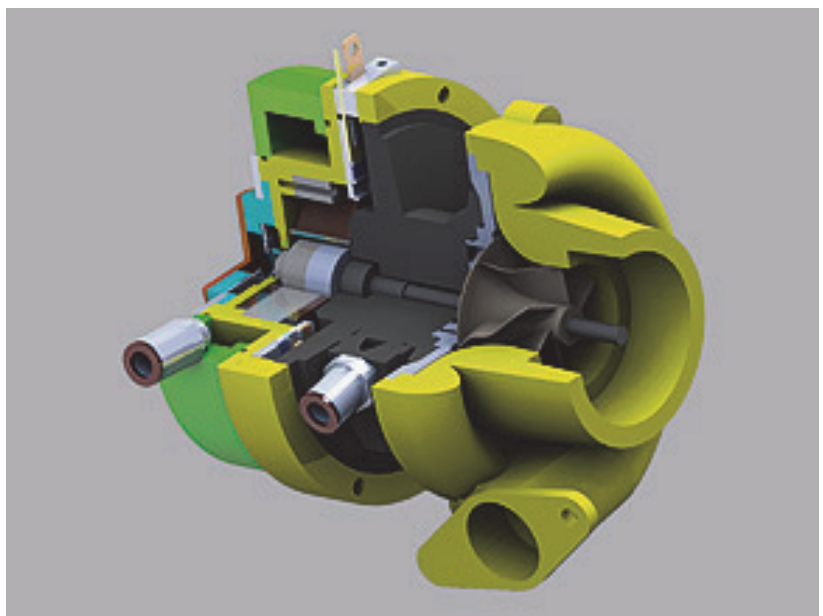

Fig.5. Electric water-cooled centrifugal compressor

Due to the high temperatures that characterize the working environment of the compressor, it was necessary to find an appropriate solution of the complete cooling system. For this purpose, the water cooling system (Figure 5) which proved to be a better option compared to standard air cooling because of its advantages:

- providing a stable temperature environment, which is important for electronic components,

- to prevent the accumulation of dirt within the bit compressor assemblies (sealed housing compressor retains water inside and outside the dirt),

- easy to install as there is a need to ensure the pipe system for supplying fresh air deep within the engine compartment,

maintenance-free.

Also today there are centrifugal compressor with additional electric actuator. These devices are characterized by the solution of setting electric axially 
between the turbine and compressor parts. The purpose of this electric motor is to compensate the delay response of the compressor. At low engine speeds is used to assist in the creation of a sufficiently high filling pressure, while at high engine speeds may be configured so that it acts as an electric power generator that consumes the kinetic energy of the exhaust gas (and thus eliminating the need for a mechanical relief valve, and ultimately, the case can be removed from service and mechanically driven by alternators). The centrifugal compressor, with additional electric motor is shown in Figure 6.

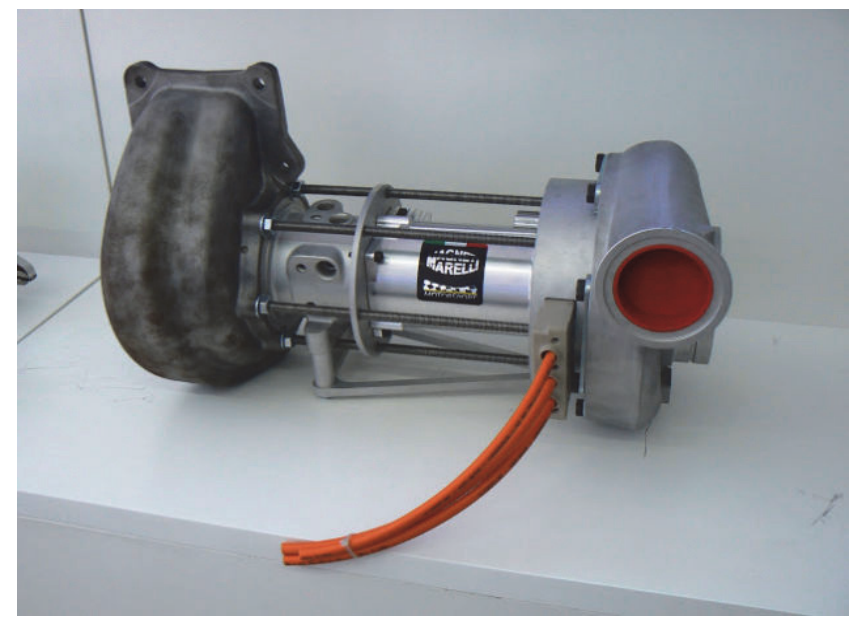

Fig.6. Centrifugal compressor with supplementary electric motor

\section{MODEL AND RESULTS}

The aim of this study was to examine possibility of installing an electric compressor on IC engine.

Testing will be conducted in two stages:

- engine operation without adding the electric compressor,

- engine with additional electric compressor.

On the following Fig. 7 was shown turbo-diesel IC engine after installation of electric compressor.

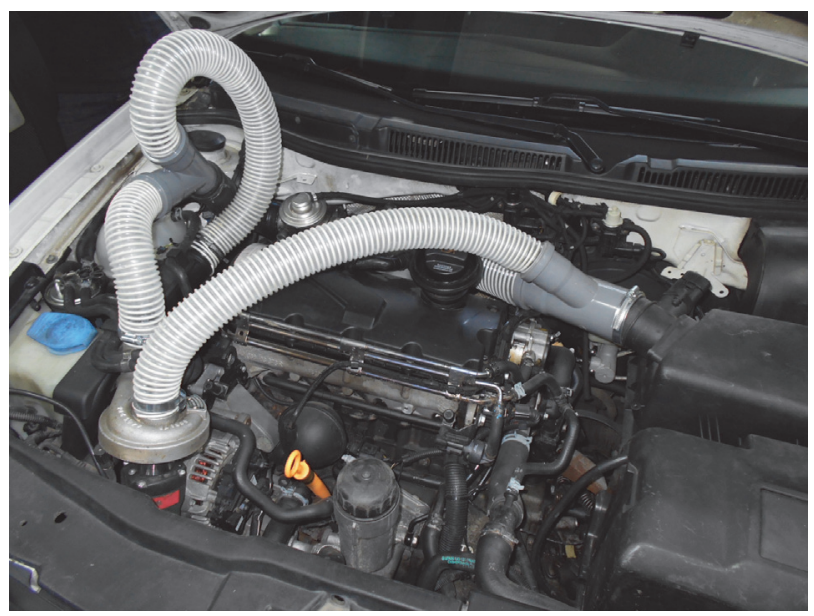

Fig.7. Tested engine after the installation of the electric compressor

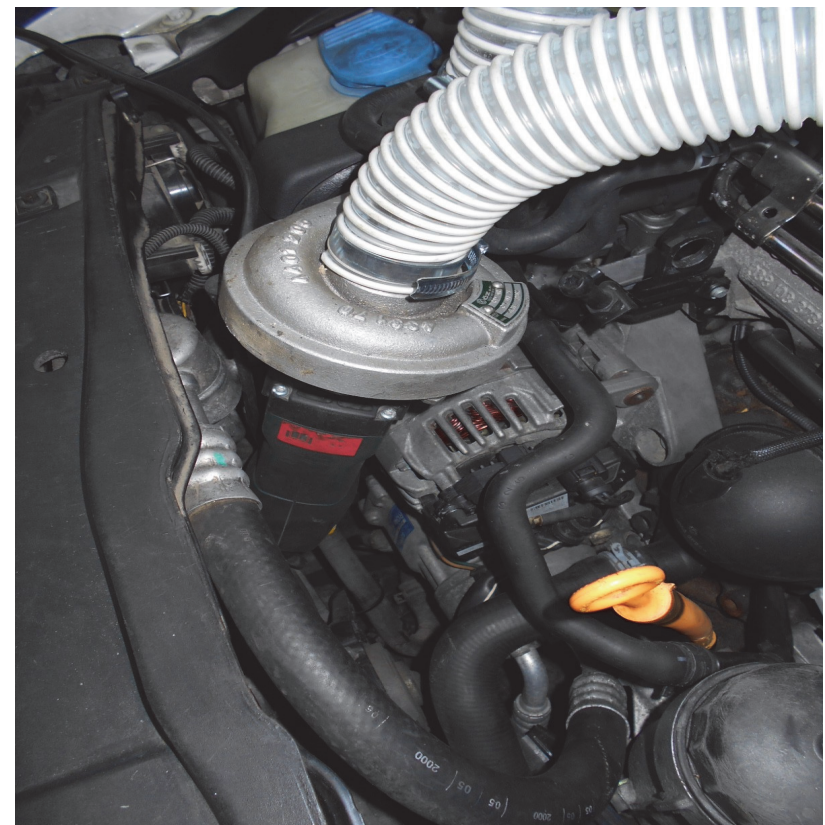

Fig.8. Electric compressor on tested engine

Compressor that was used in this study was made by manufacturer's $\mathrm{CZ}$ series $\mathrm{C} 1$, designed for use on internal combustion engine driven on diesel, LPG and natural gas. This turbo-compressor has been rebuild, the turbine wheel is removed and special adapter was installed. Characteristics of the compressor are shown in Table 1, while the characteristics of the electric motor that drives a compressor provided in Table 2 below.

Table 1. Basic compressor data

\begin{tabular}{|c|c|c|c|c|}
\hline Type & $\begin{array}{c}\text { Engine } \\
\text { power }\end{array}$ & $\begin{array}{c}\text { Engine } \\
\text { volume }\end{array}$ & Air flow & $\begin{array}{c}\text { Compressor } \\
\text { circuit } \\
\text { diameter }\end{array}$ \\
\hline $\mathrm{C} 12$ & $\begin{array}{c}20- \\
80 \mathrm{~kW}\end{array}$ & $2-41$ & $\begin{array}{c}0,02- \\
0,13 \mathrm{~kg} / \mathrm{s}\end{array}$ & $50 \mathrm{~mm}$ \\
\hline
\end{tabular}

Table 2. Basic electromotor data

\begin{tabular}{|l|r|}
\hline Nominal speed & 28,000 \\
\hline Engine power & $1,400 \mathrm{~W}$ \\
\hline Output power & $750 \mathrm{~W}$ \\
\hline Mass & $4,3 \mathrm{~kg}$ \\
\hline
\end{tabular}

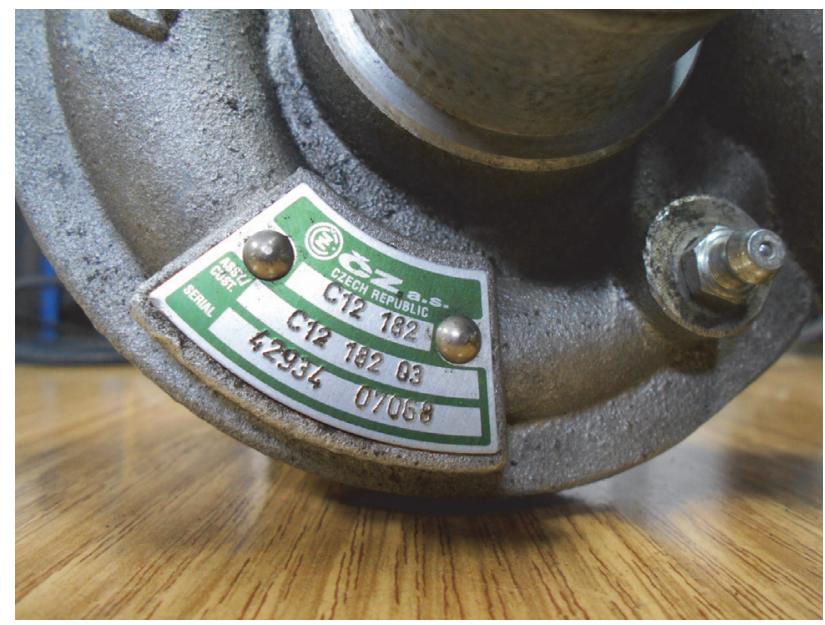

Fig.9. The compressor used in the study 
Used compressor can be seen in Figure 9, in fact this compressor is the same as in ordinary turbocharged engine but in our case it will be driven with electric motor during low rpm of engine.

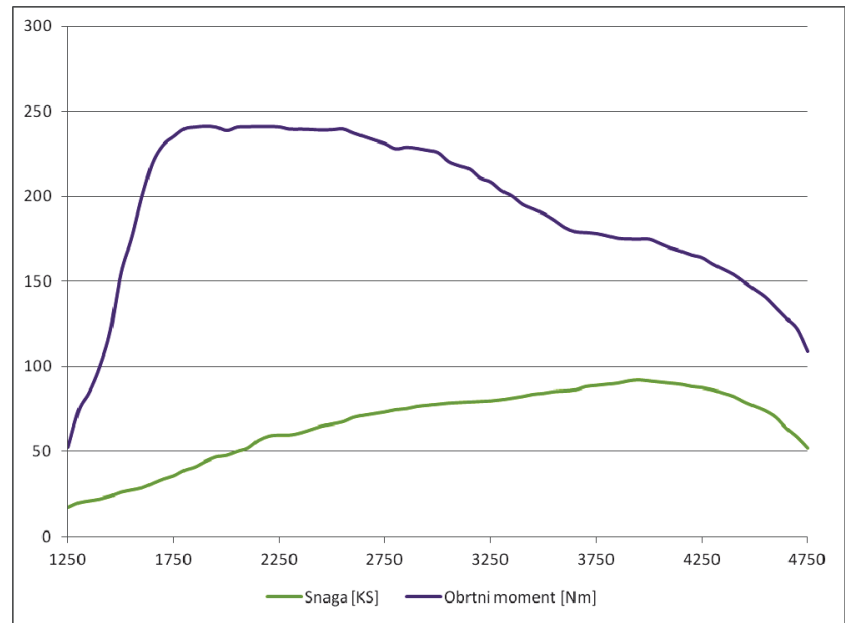

Fig.10. Diagram of power and torque for cases without electric compressor

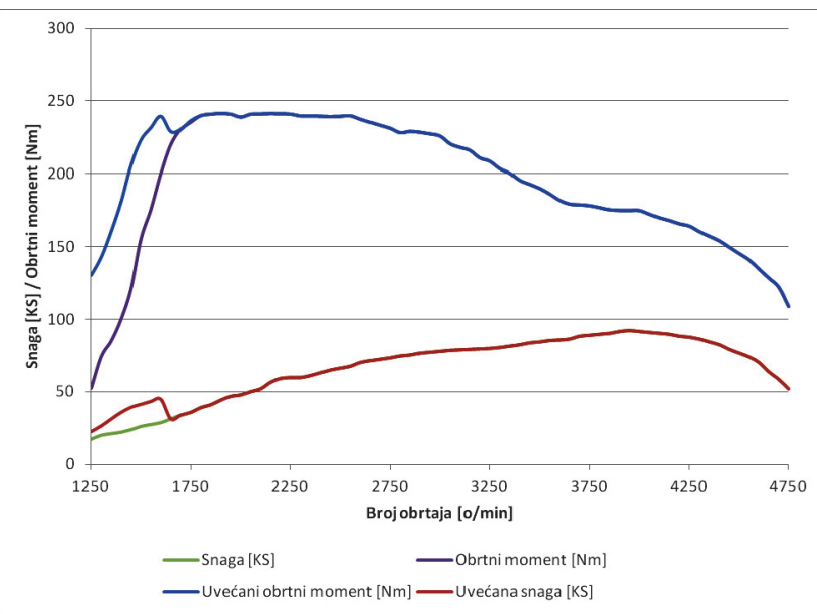

Fig.11. Comparative diagram of power and torque for cases with and without the added electric compressor

Diagram of power and torque for cases without electric compressor was shown on Fig 10. The measured values of power and torque output for a case without electric compressor shown that the maximum power is achieved at $3950 \mathrm{rpm}(68,6 \mathrm{~kW})$ and the maximum torque generated at $1900 \mathrm{rpm}$ with its value of $241,5 \mathrm{Nm}$. These values were less than those declared by the manufacturer, which is expected due to long engine exploitation as well as losses in power transmission due to the fact that the force was measured on the wheels. After the first part of the experiment where power and torque was measured with a built-in compressor by the manufacturer, in the second part of the experiment power and torque was measured with electric compressor. The analysis of the results is observed an initial increase in the value of power and the engine torque in the range of engine speed when the electric compressor is active. In order to compare test results for the both cases with and without electric compressor experimental results are shown in the following Figure 11.

\section{CONCLUSION}

In this article was presented one approach for improvement of spark ignition engine performance. In this research we found about $39 \%$ increase of torque for the given speed range of $1250 \div 1600 \mathrm{rpm}$. These results are dictated by the particular engine used in the experiment, as well as by a electric compressor as a general technical condition of the engine. The apparent decline in both curves in the comparative diagram is explained through fact that experiment was performed with a manually on/off compressor mode, forcing notable instant cut off in the compressor engine speed of 1600 rpm. These good values from experimental research of power and torque under the given conditions can be considered as expected value, yet the results of course depend on the technical condition of the engine and the used equipment. About $34 \%$ increase of the power and $39 \%$ of the torque can be expected in other engines with proper electric compressor. Described concept has several advantages over ordinary SI engines. All of these mentioned advantages show that the potential to increase the efficiency of the SI engine conditions is not yet exhausted.

\section{REFERENCES}

[1] Dorić, J. (2008). Valveless IC Engine with More Complete Expansion, Master thesis, Novi Sad.

[2] Greiter, E.M. (1976) Surge and Rotating Stall in Axial Flow Compressor System Model, ASME Journal of Engineering for Power, Vol 98 (1976), pp.190-198.

[3] Koehler, R.F. (2006). Verbrennungsmotoren Motormechanik, Berechnung und Auslegung des Hubkolbenmotors, 4. Auflage, Vieweg \& Sohn Verlag, GWV Fachverlage GmbH, Wiesbaden.

[4] Živković, M. (1976). Motori sa unutrašnjim sagorevanjem, Mašinski fakultet univerziteta $\mathrm{u}$ Beogradu, Beograd.

[5] Bhushan, B. (2002). Introduction to Tribology, John Wiley \& Sons, Inc., New York.

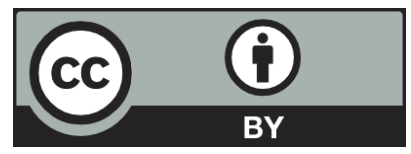

(C) 2017 Authors. Published by the University of Novi Sad, Faculty of Technical Sciences.

This article is an open access article distributed under the terms and conditions of the Creative Commons Attribution license 3.0 Serbia (http://creativecommons.org/licenses/by/3.0/rs/). 